\title{
An Application of T-X Domain Dip Filter in Extracting Water Bottom Multiples
}

\author{
Chang-Sheng Huang, Jiunn-Yih Chen, Juin-Wei Ku \\ AND \\ YU-LANG YANG \\ Geophysical Data Processing Center, Offshore and Overseas Exploration \\ Division, Chinese Petroleum Corporation, Taiwan, R.O.C.
}

(Received 18 April 1990; revised 30, June 1990)

\begin{abstract}
Multiple elimination is one of the important topics in the field of seismic data processing. Since the water bottom multiples usually interfere with the primary reflections and induce overmigration during the migration stage, we propose one simple and easy method to extract the first order water bottom multiple. This method is an extended application of the time space ( $\mathrm{T}-\mathrm{X}$ ) domain dip filter combined with the residual migration. In the area with rugged water bottom, this method is more effective, than conventional multiple suppression methods, for the suppression of multiples.

It erases the water bottom multiples from the record, but also any undesired energy. Since this mehod is applied in the post-stack stage and the recognization of the multiple is subjective, so the application of this method should be made very carefully. When parameters are properly chosen, the application of this method can make an noticeable improvement in the final results.
\end{abstract}

\section{INTRODUCTION AND PREVIOUS STUDIES}

The conventional multiple elimination techniques are all based on the facts listed below (Yilmaz, 1987):

a. The moveout difference between primaries and multiples.

b. The dip difference between primaries and multiples.

c. The frequency content between primaries and multiples.

d. The periodicity of multiples.

Multiple suppression techniques based on these criteria include the slantstack multiple suppression technique (Alam and Austin, 1981, Treitel et al., 1982), the velocity discrimination technique and the application of predictive deconvolution in the $\tau$-P domain (Taner, 1980), etc. Although these techniques 
all have sound conceptual bases, their performance is sometimes unsatisfactoy. Possible explanations may be that there are not significant moveout differences between primary reflections and multiples or that there are structural irregularities in the lateral direction (i.e. rugged water bottom). The geometry divergent correction using velocity functions may also enhance the amplitude of multiples. All these factors described above may cause the conventional suppression technique to fail in removing multiples from the seismic data.

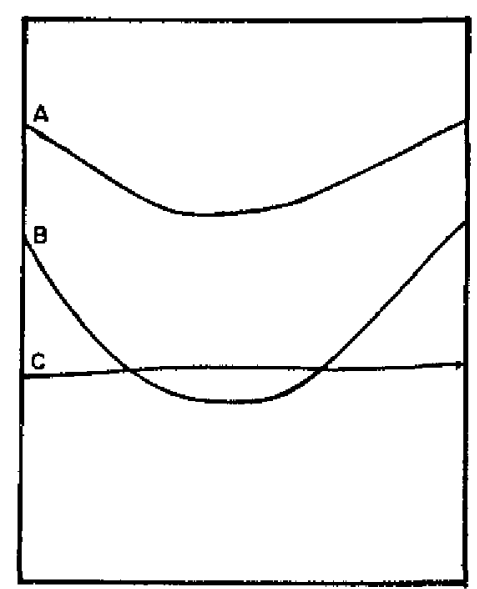

(0)

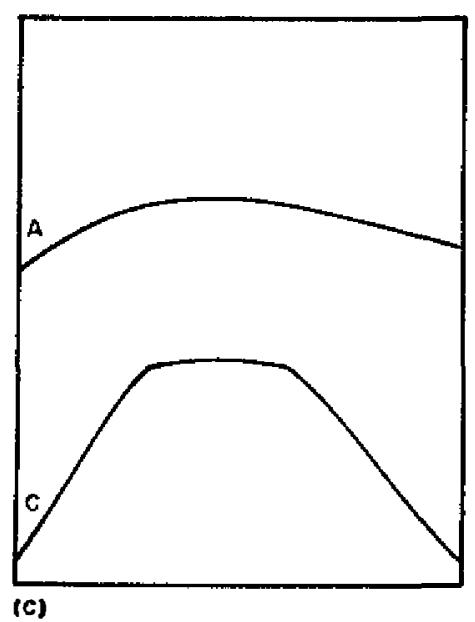

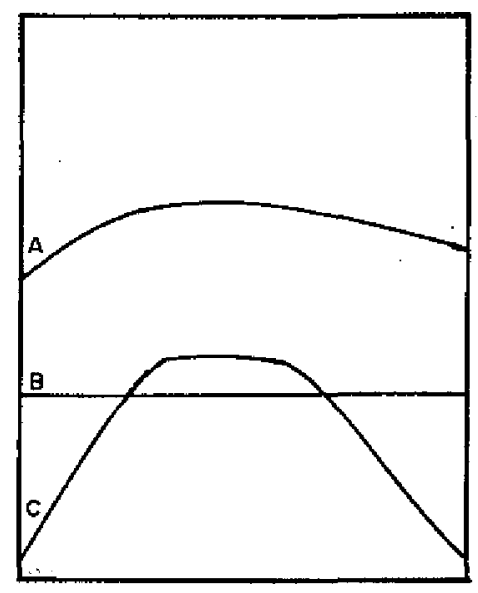

(b)

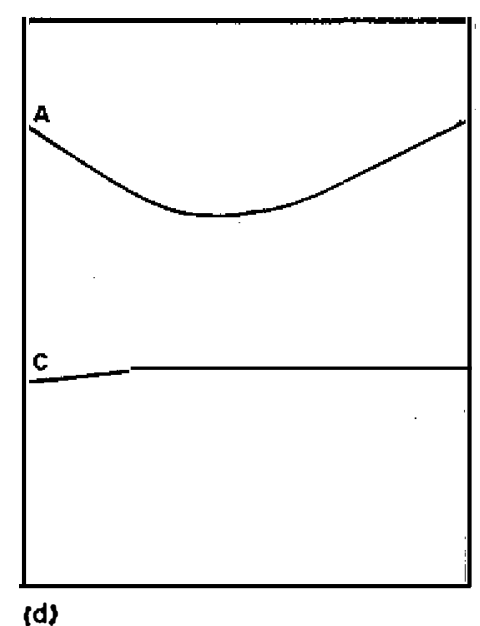

Fig. 1. Procedures of multiple extraction. Events A, B and C represent water bottom, water bottom multiple and primary reflection respectively. (a) Sketches of $A, B$ and $C$ after the first pass of migration. (b) B is flattened by time shift. (c) $\mathrm{B}$ is extracted by dip filter. (d) Correct position of $\mathrm{A}$ and $\mathrm{C}$ after the second pass of migration.

As for water bottom multiples, they can be easily removed by using a predictive deconvolution filter if the water bottom is flat. In areas with a deep and 
rugged water bottom, the prediction lag and operator length should be varied with the relief of the water bottom. These factors make it hard to decide on deconvolution parameters during the data processing procedures. Furthermore, the RMS velocity of the water bottom multiple is approximatly equal to the RMS velocity of water. This means that, if there exist multiples in the stacked section, they may cause overmigration by using the RMS velocity in migration operation and obscure the primary reflections.

Since the performance of the conventional multiple suppression technique is of ten disappointing for deep water bottom multiples one direct and easy way to extract multiples is provided in this paper. The procedure of migration is divided into two passes — water velocity migration in the first pass and residual migration in the second. Firstly, the stacked section is migrated with the RMS water velocity. In the first pass migration, the water bottom reflections and multiples are migrated to their "correct" positions (Fig. 1a). Then, the time values of the multiples are picked and digitized. With these time values, the traces are shifted to make all the multiples flat (Fig. 1b). The flattened multiples can now be removed by a T-X domain dip filter (Fig. 1c). The filtered traces have to be shifted back to their original positions (Fig. Id). Since the primaries are still not migrated completely, the whole section has to be migrated with the calculated residual velocities of the primaries (the second pass migration). After applying all these procedures, the multiples that can be recognized on the original seismic section could completely be removed.

\section{METHOD}

Two operations are involved in this paper. They are space-time (T-X) domain dip filtering and two-pass finite difference migration.

The generation of the water bottom multiple is due to seismic reflections happening more than once within the water layer (Fig. 2a). According to the number of reflections, the multiple can be defined as the first order, the second order, etc. The seismic energy can also be reflected within one layer and generate the other type of multiples such as pig-leg multiples shown in Fig. $2 \mathrm{~b}$. The multiple discussed here is concerned with the first order type, i.e. the water bottom multiple, for the occurrence of this type of multiple is easy to recognize in the seismic section.

The arithmetic equations concerned in this paper are described below :

\section{a. $T$-X domain dip filter}

The conventional dip filter is operated in a frequency-wave number ( F-K) domain. The seismic data are firstly Fourier transformed into an F-K domain 


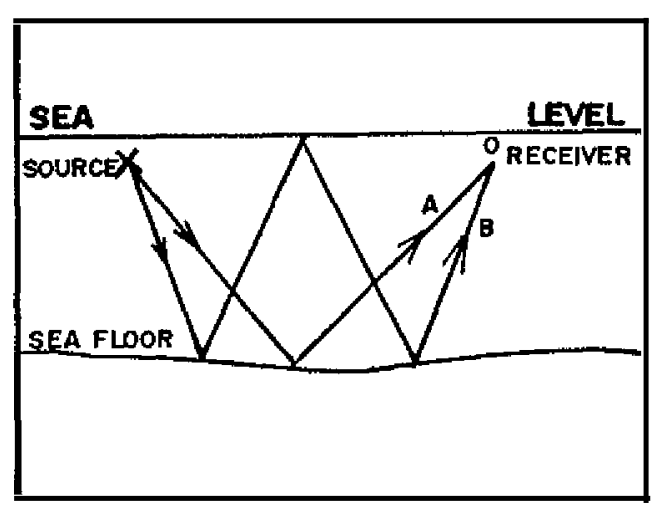

(a)

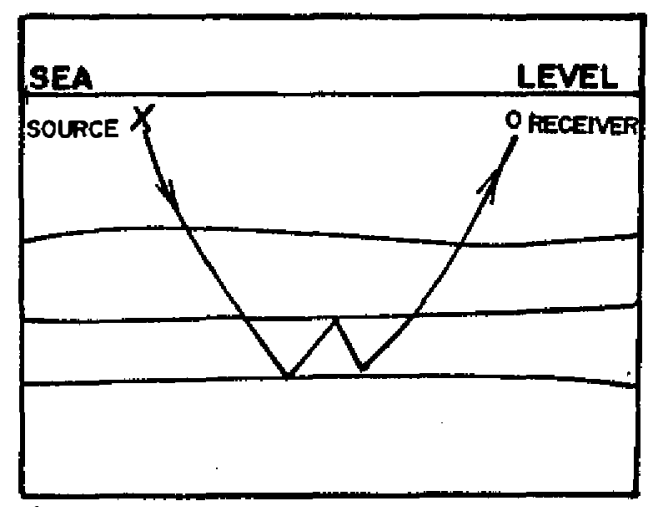

(b)

Fig. 2. Generation of multiples. (a) The primary water bottom reflection A and the first order water bottom multiple reflection B. (b) A multiple is generated within a layers.

and a filter in this domain is designed, then the filter is applied and the data are then transformed back into the T-X domain. Although the F-K dip filter is effective in eliminating dip events, it may introduce troublesome coherent noise. Furthermore, the F-K domain dip filter is usually applied for the whole seismic section. For the dip events confined in a certain time range, it is unnecessary to apply the dip filter to the whole section. Hale (1983) suggested to apply one $\mathrm{T}$-X domain dip filter only to a certain part of the seismic data that need to be filtered, with the remainder of the data being unfiltered.

Hale's Butterworth dip filter can be simplified as the Fourier transforms of the following equations.

$$
Q=\frac{P}{1+(D W / K)} \quad \text { low-dip-pass }
$$

and

$$
Q=\frac{P}{1+(K / D W)} \quad \text { high-dip-pass }
$$

where $P, Q$ are the input and output wave functions respectively, $D$ is the cutoff $\operatorname{dip}, W$ is the angular frequency and $K$ is the wavenumber. The finite difference method will transform the Fourier transformed equation into difference forms. Then the dip filtering can be simplified as the recursive solution of a tridiagonal system.

In this paper; we design one high-dip-pass filter and apply it to the flattened multiple events. For the time variant nature of this filter, the seismic data outside the time gates chosen by the user remains unfiltered. 


\section{b. Two pass finite difference migration}

The finite difference migration was first innovated by Claerbout $(1976,1985)$. This technique is derived from the finite difference solution of the scalar wave equation. Since the RMS velocities of the multiples are smaller than the velocities of the primaries, we have to migrate the multiples and water bottom reflections to their "correct" positions first by using the RMS velocity of the sea water (about $1500 \mathrm{~m} \mathrm{sec}^{-1}$ ) in order to prevent the occurrence of overmigration. This is the first pass migration. After this, the water bottom multiples will be recognized by their two-way travel times and apparent dip at about twice the time of the water bottom reflections. After all the multiples have been removed, we have to migrate the primaries into their real position since they are still in undermigrated conditions (the second pass migration). The velocities used in the second pass migration can be easily derived from the following equations:

$$
\frac{\partial}{\partial z} P\left(k_{y}, z, w\right)=i\left[\frac{w^{2}}{v^{2}}-k_{y}^{2}\right]^{\frac{1}{2}} P\left(k_{y}, z, w\right)
$$

and

$$
k_{z}=\frac{w}{v}\left[1-\left(\frac{v k_{y}}{w}\right)^{2}\right]^{\frac{1}{2}}
$$

Where $P$ is the wave function, $k_{z}, k_{y}$ are the wave numbers in $z$ and CMP direction, $w$ is the angular frequency and $v$ is the velocity function in the $z$ direction.

The 15 degrees parabolic approximation is the basis of finite difference migration. From the Taylor expansion of equation (4), we get

$$
k_{z} \approx \frac{2 w}{v}\left(1-\frac{v^{2} k_{y}^{2}}{2(2 w)^{2}}\right)=\frac{2 w}{v}-\frac{v k_{y}^{2}}{4 w}
$$

Practically, the migration operation used is still performed in the time domain ( time migration ), and

$$
w_{\tau}=\frac{v k_{z}}{2}
$$

where, $w_{\tau}$ is the output angular frequency. By substituting equation (6) into (5), we have

$$
w_{\tau}=w-\frac{v^{2} k_{y}^{2}}{8 w}
$$

The first pass output angular frequency will be

$$
w_{1}=w-\frac{v_{1}^{2} k_{y}^{2}}{8 w}
$$




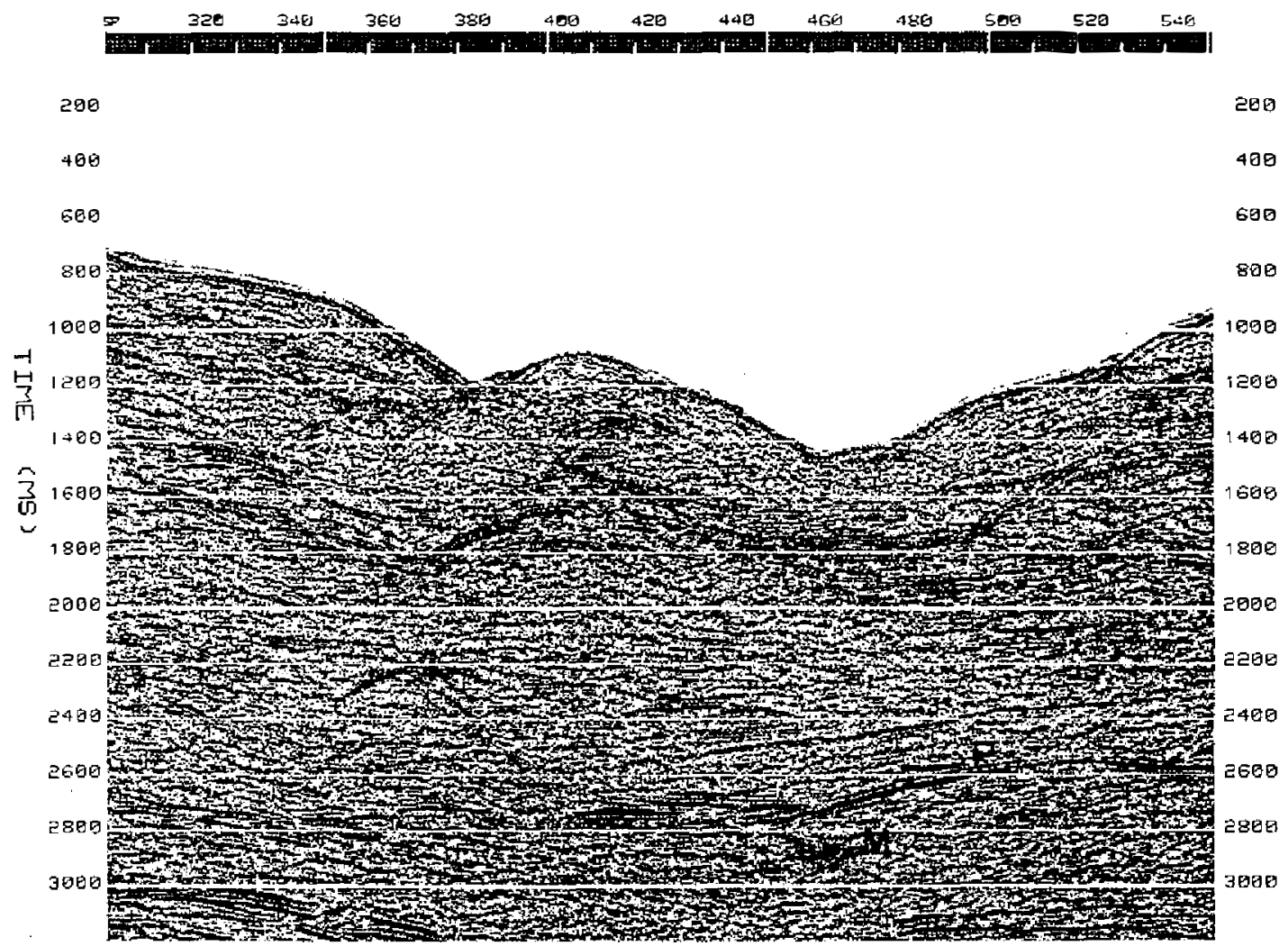

Fig. 3. The final stack section of Example 1. The multiple M located at 2900 $m$ sec can not be recognized clearly in this figure.

and the second pass output angular frequency will be

$$
w_{2}=w_{1}-\frac{v^{2} k_{y}^{2}}{8 w}
$$

Let $w$ be equal to $w_{\tau}$. From equations (7), (8) and (9), we get

$$
v^{2}=v_{1}^{2}+v_{2}^{2}
$$

so that the second pass velocity is

$$
v_{2}=\sqrt{v^{2}-v_{1}^{2}}
$$

The equations listed above are only parts of the mathematical foundation for the residual migration.

\section{EXAMPLES}




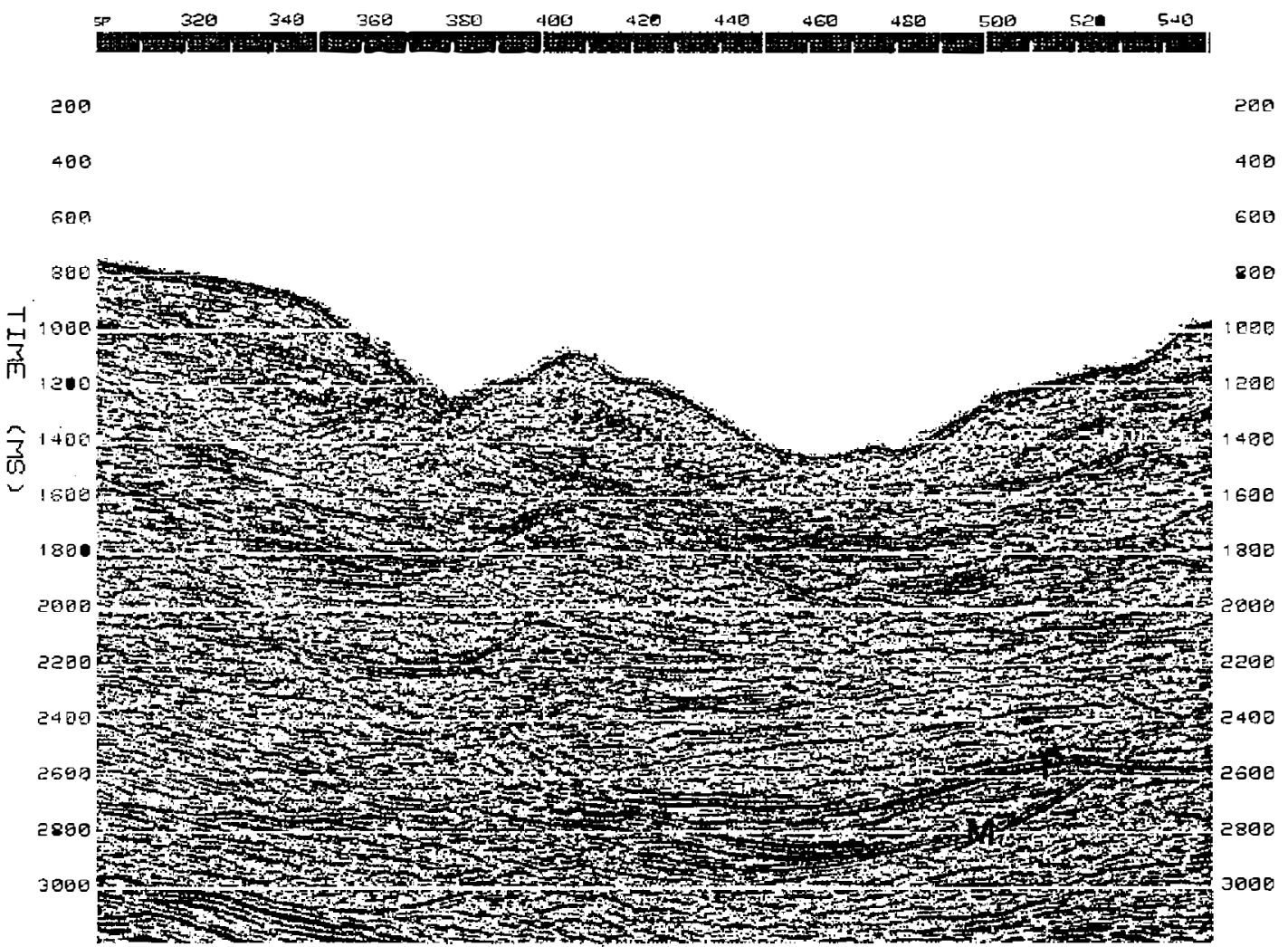

Fig. 4. The migrated section of Fig. 3 without any multiple extraction procedure being applied. $M$ is water bottom multiple, $P$ represents primary refiection. Overmigration of $\mathrm{M}$ has already intersected with $\mathrm{P}$ at $2550 \mathrm{~m} \mathrm{sec}$.

The water bottom multiples occurring in the deep and rugged water bottom have long been a troublesome problem in order to process the marine seismic data. Since the conventional methods sometimes failed to solve this problem, we have developed the technique described above to remove these multiples existing on the seismic records. After applying this technique to the seismic data, the quality of the resulting seismic sections becomes noticeably improved.

We are going to show two examples here which were obtained in a deep water survey of the southern Taiwan Straits. Due to the deep and rugged water bottom in this area, the long period multiples appear on most of the seismic lines.

For the first example, Fig. 3 represents the final section of a seismic line. Figs. 4 to 7 represent the results of every main step included in this technique.

Fig. 4 is the migrated section of Fig. 3 without any multiple elimination being applied. Obviously, the multiple $M$ has been overmigrated and interfered with the primary $\mathrm{P}$ in this figure. Although mutiple $\mathrm{M}$ can be identified, the 


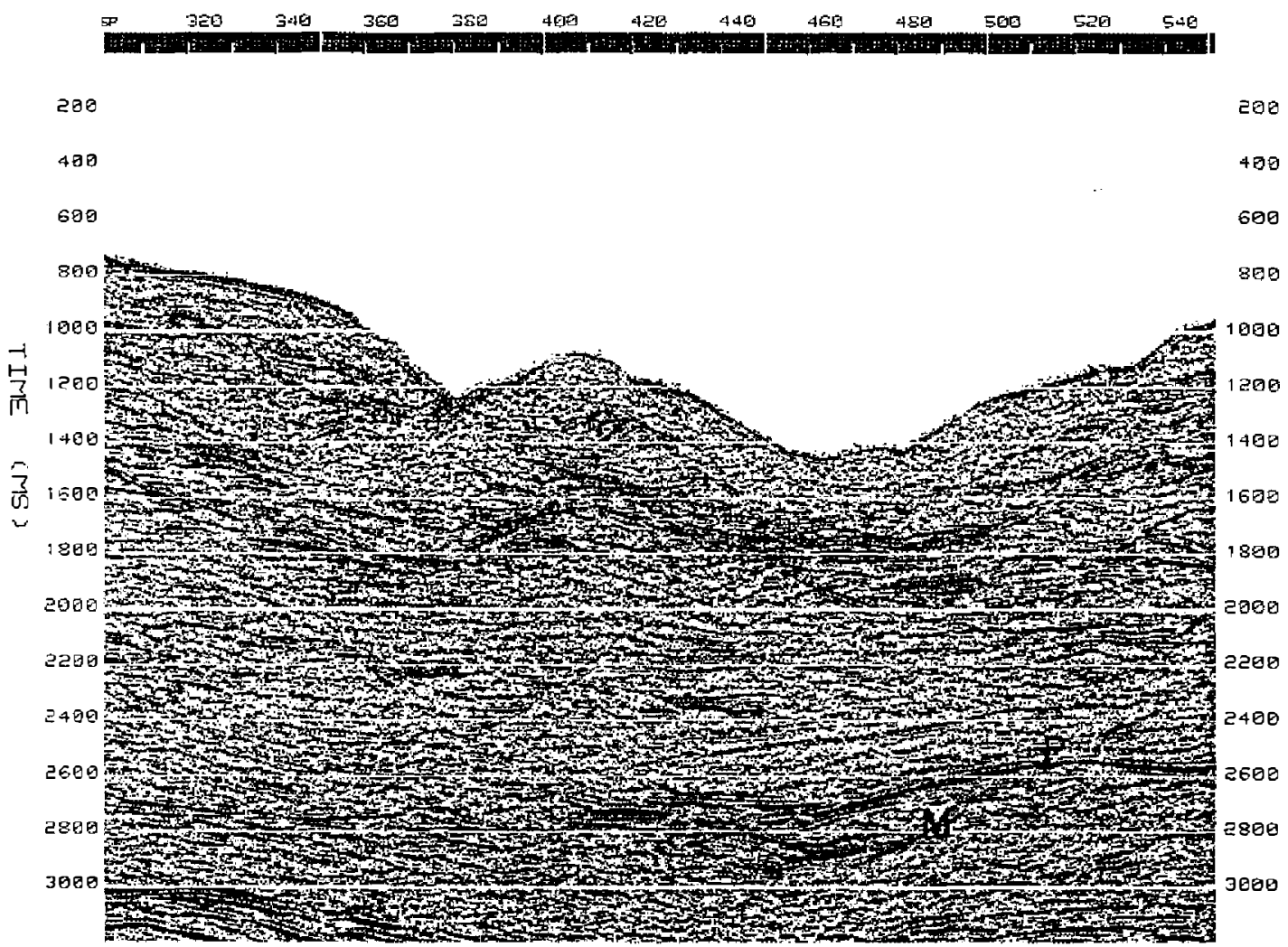

Fig. 5. After the first pass migration operation, the multiple $\mathrm{M}$ can be identified clearly in this figure.

superficial appearance of multiple $M$ is still hardly defined when compared to Fig. 5.

Fig. 5 is the first-pass migration section of Fig. 3 with the use of the RMS velocity of the sea water. The multiple $M$ occurring at about twice the two-way travel time for the water bottom reflection can easily be recognized in comparison with Fig. 4. The reason is that the migration operation has moved the multiple $\mathrm{M}$ and water bottom reflection to their "true" dip positions and their appearance has some kind of similarities.

Fig. 6 is the section where the multiple $M$ has been removed by the dip filtering and shifting procedures. The dip filter used is a high pass type with $\operatorname{dip} 2 \mathrm{~m} \mathrm{sec} /$ trace having a time gate of $100 \mathrm{~m} \mathrm{~s}$. The seismic events greater than this dip angle or outside the time gate are unaffected.

Fig. 7 is the result of the migration of Fig. 3. All events have been moved to their correct positions after the second pass migration operation. Comparing Fig. 7 to Fig. 4, the quality of this section has obviously been improved, especially the events between 2 seconds to 3 seconds and the overmigration of 


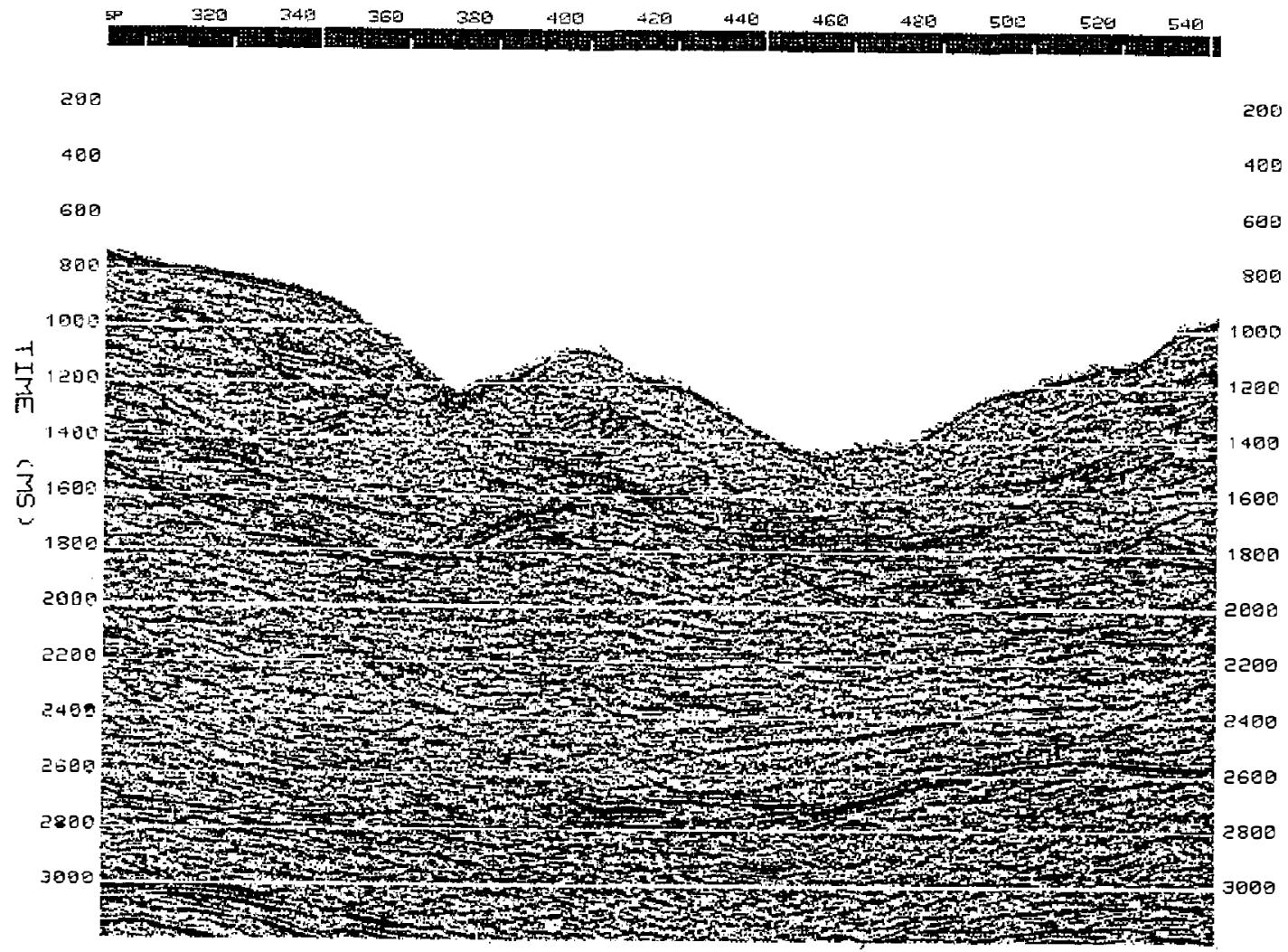

Fig. 6. The migration section with the multiple $M$ being removed. Sorne events do not occur in their correct positions.

the multiple has been avoided effectively.

As a second example, Figs. 8 and 9 are the results of migrated sections for another seismic line. The difference between them is that to Fig. 9 has been applied the multiple suppression technique introduced in this paper. In Fig. 8, the multiple $\mathrm{M}$ is located at the position about double the two-way travel time of the water bottom reflection and extended downward. Although this multiple does not induce any overmigration effect, the trend has intersected with the primary reflections and degraded the quality of processing. The filter used here is of dip angle $2 \mathrm{~m} \mathrm{~s} /$ trace with a time gate of $100 \mathrm{~m} \mathrm{~s}$. It should be noted that the seismic data outside the multiple $M$ still preserved their original superficial appearances even after the dip filter had been applied.

\section{DISCUSSIONS}

This paper provides an alternative method for extracting multiples from seismic records, and preventing overmigration during the migration procedure. 


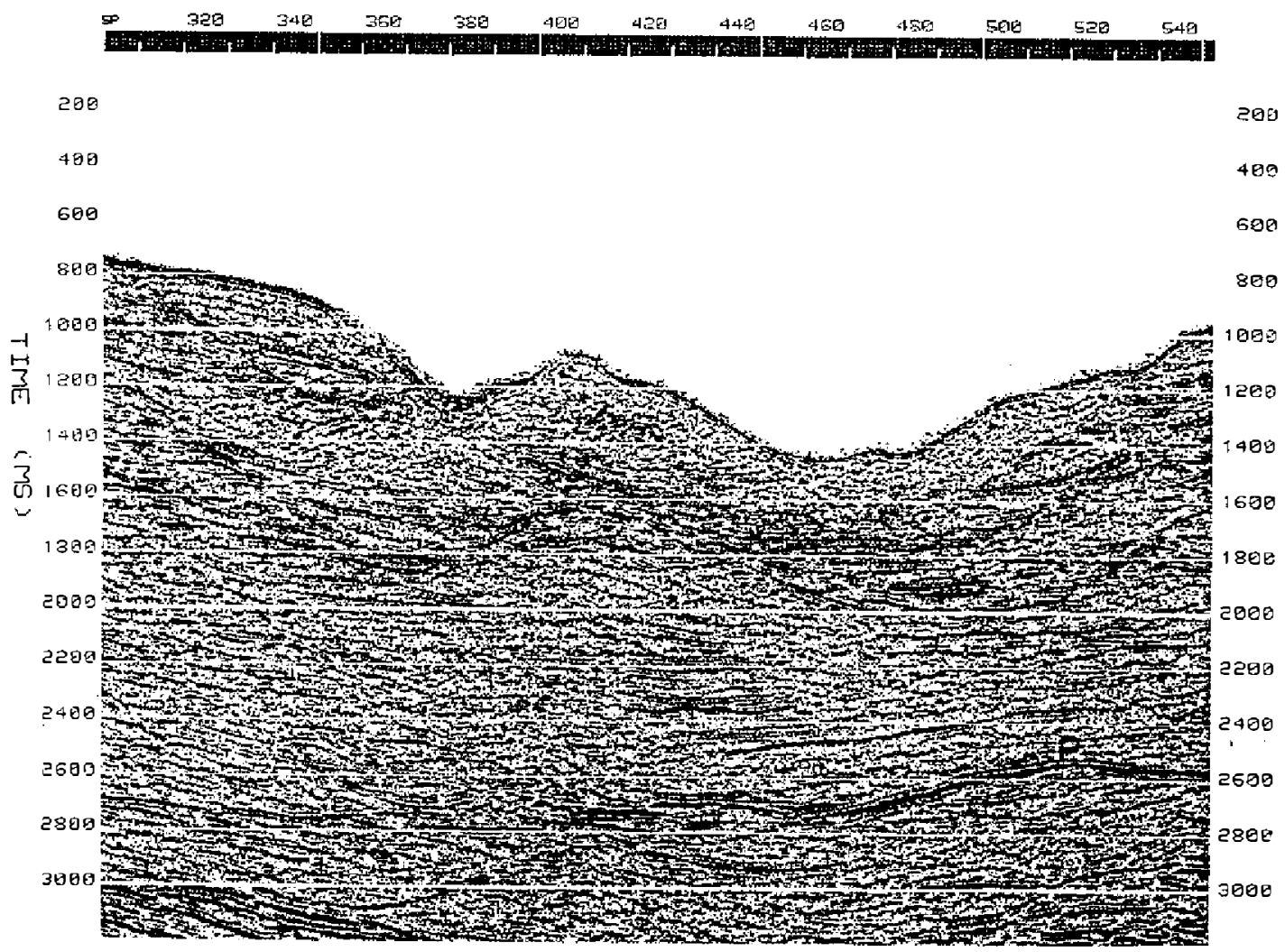

Fig. 7. The final resulting section of multiple extraction, after the second migration, shows that all the events have been migrated to their true spacial positions.

Compared with other before-stack multiple suppression technques, this method is simple and time saving, especially, when the water bottom of a survey area is rugged.

a. When multiples embedded in or parallel to primaries or the sea bottom are not varied too much, it is difficult to distinguish any differences between them. The predictive deconvolution is prefered in this condition, especially, if the sea bottom of survey area is flat.

b. The parameters of the T-X domain dip filter should be selected carefully. With too wide of a time gate or too steep a high pass dip, the filter will harm the data which are not to be filtered.

c. The recognization of the multiple is very subjective, so the multiple must be prudently defined. Events which are not related to multiples must not be removed.

d. If the overmigration of the multiple is not serious after the migration procedure with RMS velocity functions of the primaries, the T-X domain dip 


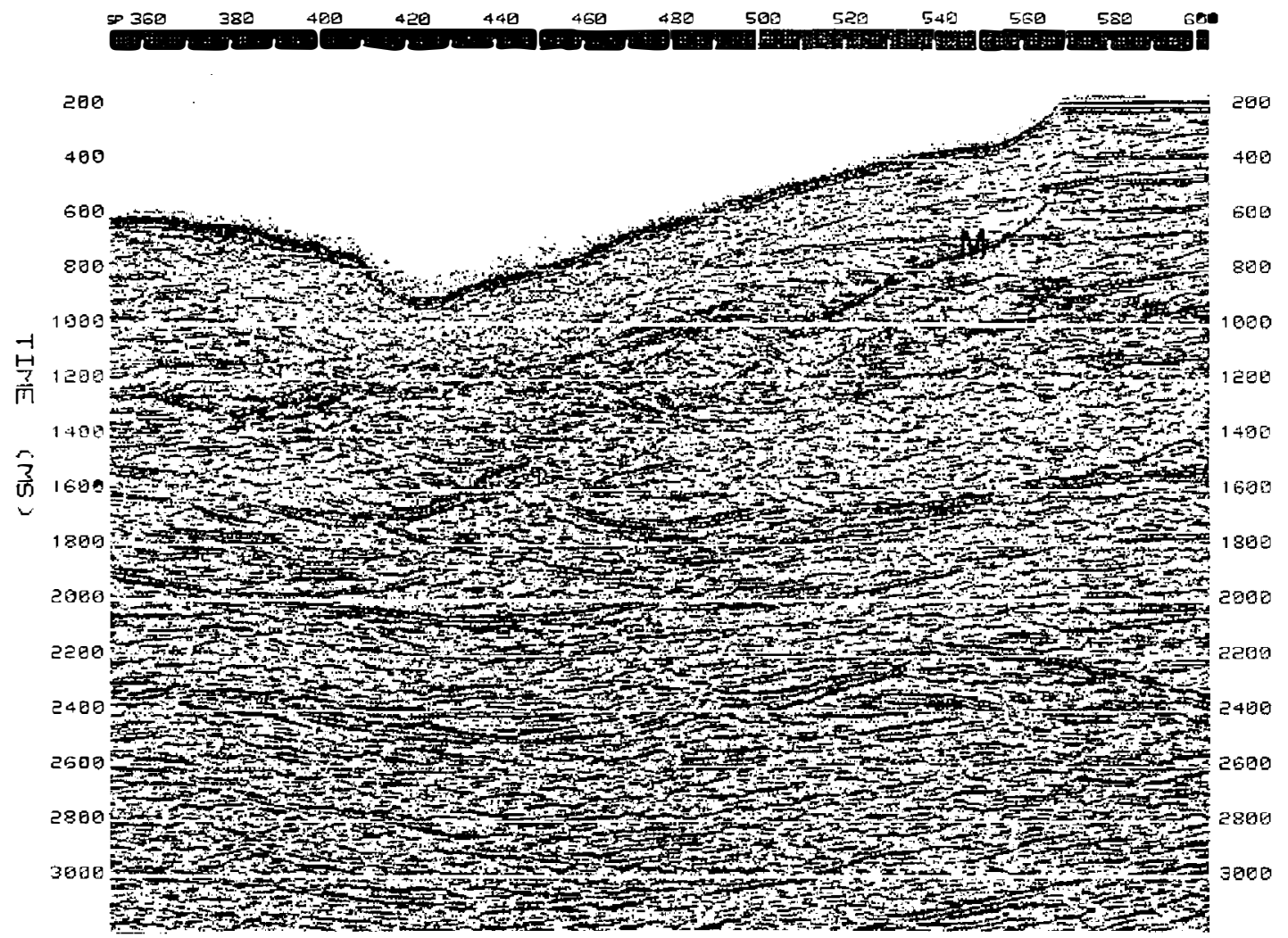

Fig. 8. The migrated section of another line without applying any multiple extraction procedures. The multiple $\mathrm{M}$ extending downward is obviously seen in this figure.

filter can even be applied into the migration section directly and there is no need to migrate seismic data with the two pass mode.

By carefully using this technique, all multiples can be removed and the quality of the seismic section can be obviously improved. It is suggested that this technique be applied in parallel with other multiple suppression techniques. Even if all other methods failed, this technique still can provide satisfactory results.

\section{CONCLUSIONS}

The technique introduced here can be considered an extended application of the T-X domain dip filter. The time variant characteristics of the dip filter and two-pass finite difference migration are combined to extract water bottom multiples which are hard to remove with the other suppression techniques. This technique can also be applied in other respects, for example, to remove any 


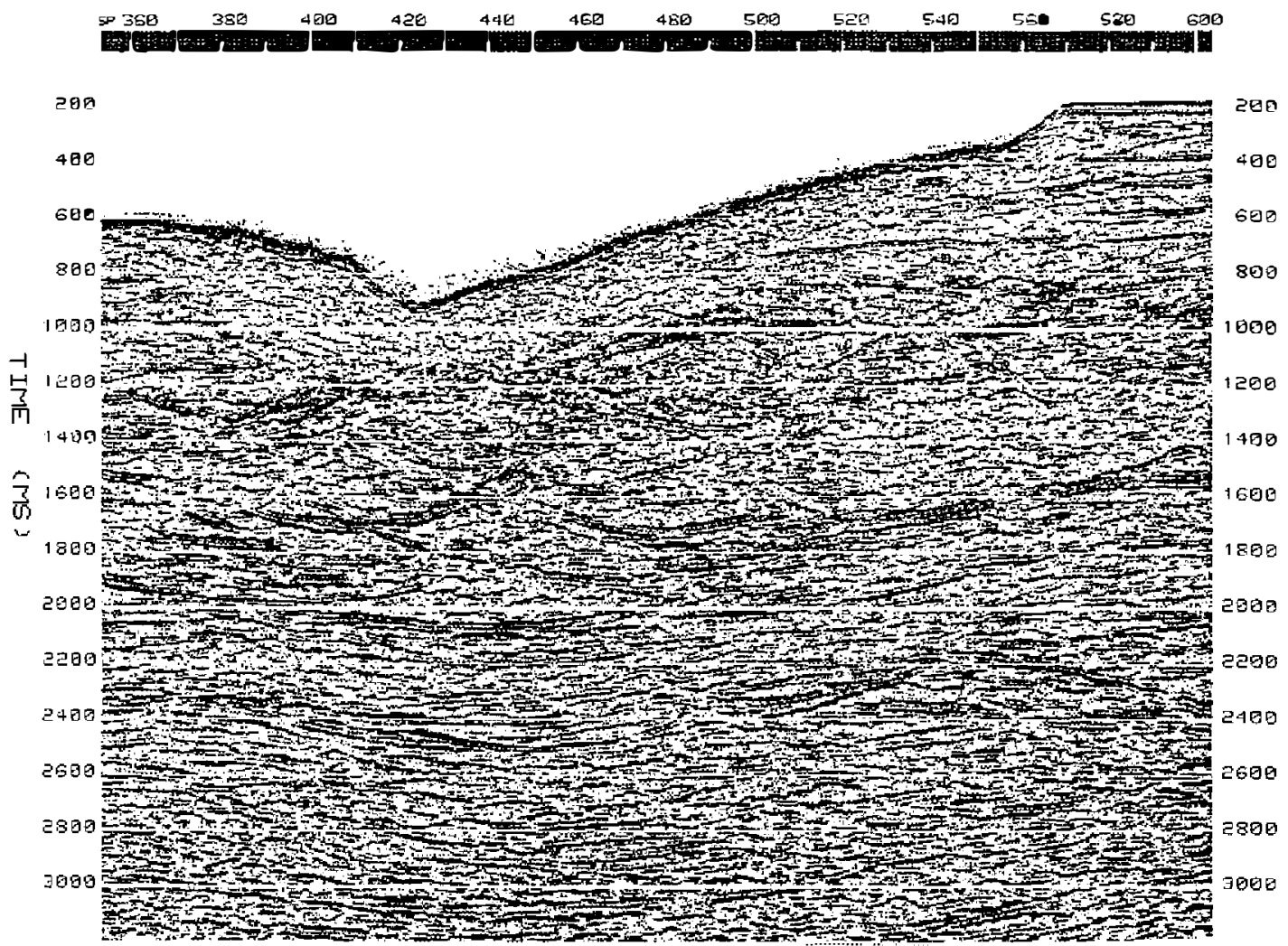

Fig. 9. The same migrated section of Fig. 8. The multiple $M$ has been removed. Note that residual parts beside multiple $M$ in $F i g .8$ remain unaffected.

unwanted coherency energy which exists on a seismic section.

Since this technique removes multiples directly from the stack section, it has to be applied carefully. With the parameters properly chosen by the users, the application of this technique can extract multiples completely from the seismic section.

Acknowledgements. The authors wish to give our sincere appreciation to Dr. F. C. Su, and Mr. W. S. Chen, chief director and deputy director of the Geophysical Data Processing Center, OPED, CPC, for their encouragement and guidance. We are also grateful to Dr. Y. S. Pan, advisor of the Chinese Petroleum Corporation, for his careful reviewing of the manuscript and suggesting some valuable improvements.

Deep gratitude is given to all the members of operating group in this center, for their help in data processing, Mr. D. H. Hsiuan of EDRC, Mr. S. C. Chen and Miss C. J. Yang of OPED, CPC, for their assistance in plotting. 


\section{REFERENCES}

Alam, A and J. Austin, 1981: Multiple suppression using slant atack. Tech. Rep., Western Geophysical company.

Claerbout, J. F., 1976: Fundamental of geophysical data processing, McGrawHill Book Co..

Claerbout, J. F., 1985: Imaging the earth interior, Blackwell Scientific Publication.

Hale, Dave and J. F. Claerbout, 1983: Butterworth dip filter. Geophysics, 48, 1033-1038.

Taner, M. T., 1980: Long-period sea-floor multiples and their suppression. Geophys. Prosp., 28, 30-48.

Treitel, S., P. R. Gutowski and D. E. Wagner, 1982: Plane wave decomposition of seismograms. Geophysics, 47, 1375-1401.

Yilmaz, O., 1987: Seismic data processing. Soceity of Exploration Geophysicists. 


\title{
時空領域濾波器在消除海底複反射方面之應用
}

\author{
黃昌盛 陳俊逸 顧駿偉 楊育良 \\ 中國石油公司海域及海外石油探勘處 \\ 地球物理資料處理中心
}

\section{摘要}

海底複反射之消除一直是震測處理過程中令人困摄的問題。海底複反射之存在，不僅干 擾了地層的反射訊號，在移位處理時，也會因爲速度因素，導致過度移位的現象。爲此我們 提出一㮔簡易的海底複反射消除方法。本方法主要是利用剩餘移位方法, 再配合時空領域 ( $\mathrm{T}-\mathrm{X}$ ) , 㑯角濾波器, 將震剆剖面上可以辨認出的海底複反射摘取消除之。尤其在海底地形 崎嵓地區，本方法較其他傳统複反射摘除方法更能有效地消除海底複反射。

本方法不僅對一般海底複反射的摘除有效, 對於副面上其他多餘能量亦能有效地加以去 除, 但由於摘取之過程是在重合後之副面進行, 且複反射之選取亦輘爱主觀, 所以在應用本 方法時必須十分小心謹値。只要在應用時小心地選用適宜的參數, 剖面的品質必可獲得相當 的提升。 